\title{
Unemployment and Economic Growth in Ethiopia
}

\author{
Abiy Serawitu \\ Dire Dawa Management and Kaizen Institute, Dire Dawa, Ethiopia
}

\begin{abstract}
Unemployment is one of the major bottlenecks of economic growth in Ethiopia. This study examines descriptively the relationship between unemployment and economic growth (GDP) by relating Okun's law prediction with graphical trend analysis. The result indicated that unemployment has a negative impact on Ethiopia's economic growth where an increase in unemployment leads the decline of real GDP. To reduce the negative impact of unemployment, and expand the employment generating mechanisms like by strengthening investment in both agricultural and nonagricultural sectors that absorb more labor force; the study recommends adoption of more employment generation mechanisms, addressing the labor market's failure \& improving the labor force productivity, improving agricultural productivity \& increasing its linkage with other sectors.
\end{abstract}

Keywords: Unemployment, economic growth

DOI: $10.7176 / \mathrm{DCS} / 10-3-03$

Publication date:March $31^{\text {st }} 2020$

\section{Introduction}

Unemployment is a key macroeconomic indicator that serves as primary diagnosis to test the health and growth of an economy (Aurangzeb and K.Asif, 2013; Bean, 1998).Unemployment mostly regarded as "foregone output" because it takes away the government of necessary resources needed to develop the economy. The unemployed will not get enough money \& government loses revenue. Instead government spend resource in different types of welfare to upkeep the unemployed. Consequently, it entails lost revenue to the government that it would have raised if more people had been working.

On the other hand, the longer the unemployment period, the more the employed lose their skill, causing loss of human capital that to contribute for the economic development of the country. As an alternative, Engaging in illegal \& anti - social activities (like drug trafficking, violent crimes, unsafe- sex...), and increasing individual's vulnerability to malnutrition, illness, mental stress, loss of self - esteem, \& leads to depression. So, it can be regarded as an element of vicious circle with poverty, low education, high dependency, poor health, \& the like.

a variety of measures have been taken to get better the country's economic growth \& people's living standard there by reducing unemployment. Under the Dergue Regime, programs like "Zemecha", Land reform, Resettlement of peoples in poverty prone areas, \& the like implemented. Under the current government, programs like SAP, PASDEP, and currently GTP, and the like implemented and contributed their part in the process of fostering the growth \&people's living standard improvement. Despite these efforts, the economy is still unable to create equitable employment opportunities for the rapidly increasing labor force supply. Presently, people are extremely migrating out of the country mainly because of unemployment (the economist, 2011).

The study is largely empirical in nature, relying on critical analysis of data and literature. The study heavily relies on the statistical data of the country's Central Statistical Agency (CSA) for the period 2009-2018. Other sources of data include from trading economics. Com "Ethiopian unemployment rate (1999-2019)"

\subsection{Statement of the Problem}

The Mses sector is believed as an engine of economic growth, poverty reduction, and social development owing to its consequence on reduction of unemployment, poverty reduction and income generation (IMF, 2015)). Likewise, MSEs Strategy in Ethiopia is also implemented to achieve it According to Dire Dawa Administration MSEs Development Agency 2018/2019 final report revealed that, small manufacturing enterprises had been still remained little in its job creation as compared to others MSCs sectors since 2009. By the same report it was also indicated that, out of the five MSEs Sectors (namely manufacturing, constriction, trade, service and urban agriculture), service and trade sectors created high job opportunity accordingly.

Previously, Admasu Abera (2012), conducted research at Arada and Lideta SubCities, Addis Ababa on factors affecting the performance of micro and small Manufacturing enterprises, the study was used profitability index of measuring the performance (the dependent variable) of MSEs and used micro and small enterprises as a target of conducting the research .

.Kinyua(2014),conducted a research objectively to investigate on factors affecting the performance of small and medium enterprises in the Jua Kali sector Nakuru town in Keny.

The study was used Ologit and micro and small enterprises as a target of conducting the research. Solomon Worku(2004), carried out research on socio economic determinants of small manufacturing enterprises ' growth at Addis Ababa, used multiple regression model and 14 dummy independent variables to study the research and also, used CAGR. 
This research is conducted to fill the methodological and the target gap of the aforementioned study. That is to say, the researcher differ on using manufacturing enterprise as a target and compound average growth rate to measure the performance (dependent variable) variable

\subsection{Objectives of the Study}

The main objective of the study is to analysis descriptively the trends of real GDP and unemployment growth rate of the country total in general, and examine nature unemployment growth rate in urban areas in particular (20092018 )

\subsubsection{Specific objectives of the study}

$>$ To analysis descriptively the growth trend relationship between Real GDP and unemployment

$>$ To examine the nature of regional urban unemployment growth rate and their contribution of to the country total

\subsection{Research Questions}

$>$ What is the growth trend relationship between real GDP and unemployment growth rate

$>$ What is the nature of regional urban unemployment growth rate in relation to the country total

\section{Literature Review}

\subsection{Definition of unemployment}

According to the ILO, employment refers to "persons who during a specified brief period such as one week or one day, (a) performed some work for wage or salary in cash or in kind, (b) had a formal attachment to their job but were temporarily not at work during the reference period, (c) performed some work for profit or family gain in cash or in kind, (d) were with an enterprise such as a business, farm or service but who were temporarily not at work during the reference period" (ILO,1982 pp.2- 3).

Furthermore,ILO (2011) classified unemployment in the following three criteria: (i) without work (ii) available for work and (iii) seeking work (ILO, 2011).According to CSA (2018), this definition varies in the context of developed and developing countries. In the developed countries where the labor market is largely organized and labour absorption is adequate, unemployment is measured based on the standard definition of the seeking work criteria that is having taken active steps to search for work during specified reference period. On the other hand,in developing countries like Ethiopia, where there is no strong labour market information ,labour absorption is inadequate and where the labour force is predominantly self-employed, the standard definition with its emphasis on seeking work criteria is somewhat restrictive and might not fully capture the prevailing employment situation. So, in order to measure the unemployment depending on the existing labour market situations special provisions are made to relax the definitions. These are partially and completely relaxed definition of unemployment. The relaxed definition which measures unemployment in relation to" without work" and "availability for work" criterion is found to be more plausible in most developing countries. The relaxed definition of unemployment, which relatively suits the Ethiopian labour market situations, includes persons who had no work but available for work. They may either seeking work or not seeking/discouraged job seekers .discouraged job seekers are those unemployed who want a job but not taking any active steps to search for work because they thought that job is not available in the labour market.

According to the report of CSA (2018) urban -employment-unemployment survey, Unemployment rate is the most commonly used indicator of the labour market, is defined as the proportion resulting from dividing the total number of unemployed persons aged ten years and above by the corresponding labour force, which itself is the sum of the total persons employed and unemployed. As per the the June 2018 survey result revealed that unemployed population in urban areas of the country was1,770,294 with unemployment rate of 19.1percent. This means that about 19 persons are unemployed out of 100 economically active persons aged ten years and above.)

\section{2., Unemployment and Economic Growth}

Okun's law predicts how a rise in unemployment affects gross domestic product (GDP), where a percentage increase in unemployment causes a $\%$ fall in GDP. This is a widely accepted view in economics that the growth rate of the Gross Domestic Product (GDP) of an economy increases employment and reduces unemployment. The three most important elements for the economy overall growth are productivity, income distribution and unemployment. This theoretical proposition relating output and unemployment has been proposed by Okun (1962). This relationship is among the most famous in macroeconomics theory and has been found to hold for several countries and regions mainly, in developed countries. He emphasized that as a result of changes in aggregate demand, industry changes their production pattern which leads to changes in demand for labour which alter the unemployment rates. This empirical relationship is a major part of every traditional macro-model as the aggregate supply curve is derived by combining Okun's law with the Phillips curve. Moreover, this relationship has also important implications for macroeconomic policy. It is simply very interesting to know the growth rate necessary 
to reduce unemployment (if this is even possible). Furthermore, the effectiveness of disinflation policy depends on the responsiveness of unemployment on the output growth rate (sacrifice ratio).

\subsection{Empirical literatures}

The relation between economic growth and unemployment has been a topic of interest in economic research for decades. The problem of unemployment is still a key problem for economists to handle as every economy aims to achieve higher economic growth by reducing level of unemployment. A number of empirical studies, conducted to examine the relation, and impact, between unemployment and economic growth, presented as follows.

Arthur Okun (1962) investigated the relation between unemployment and economic growth of USA. The result indicated a significant negative relation, and recommended for improvements in output level. Seyfried (2005) investigated the relation between economic growth and employment in ten selected developed countries over the period 1990 up to 2003. The result indicated a negative relation between economic growth and unemployment where unemployment reduces from to 0.61 percent because of one percent increase in economic growth. Hussain, at al. (2010) also examined the relation between economic growth and unemployment in Pakistan for the period 1972 - 2006 using Johansen cointegration and VECM. The result conform existence of both long run and the short run negative relation between unemployment and economic growth.

Osinubi (2005) as well examined the impact of economic growth on unemployment and poverty in Nigeria using annual time series data (1970- 2000) and using a three stages least square (3SLS) estimation. The variables selected for the study were unemployment, inflation, and index of agricultural production, index of petroleum production, money supply, exchange rate, and changes in real GDP, savings, work stoppages and trade disputes. The result reveled that growth is negatively related to poverty and positively related to unemployment against to "Okun's Law". The study recommended policy makers to reduce the income inequity to overcome poverty and low growth in Nigeria .Noor et al., (2007) also investigated the impact of economic grown unemployment in Bangladesh over the period of 1970 to 2004 and using ordinary least squares. The result showed that economic growth has negative impact on unemployment. Extra researchers also investigated empirically the impact of unemployment on economic growth such as Amino, et al (2013) for Nigeria, UK Essay (2008) for EU countries, Maria J., et al (2012) for Peru, Rafiq M., et al (2010) for Pakistan; all found that economic growth and unemployment were negatively related. El - Agrody et al. (2010) emphasized on the economic study of unemployment and its impact on Egypt's GDP (1994- 2004), using Simple and multiple linear regression analysis and involving nine variables viz., privatization, population, consumption, expenditure, interest rates, exchange rates, technology, agricultural domestic product, real wage rates, and agricultural investment. The results revealed a significant positive impact of unemployment, investment, exchange rate and average per capita share of GDP on the Egypt' s GDP. Privatization and population growth were indicated as the main reasons of increasing unemployment. The study recommended for revision of privatization policy and reduction of the interest rates in order to lower the agricultural unemployment. The above empirical studies conformed significant negative impact of unemployment on economic growth. Hence, taking the above literatures as a hint and base line, this study empirically investigates the impact of unemployment on economic growth in Ethiopia.

There are many literature reviews on unemployment conducted in different countries but most of the studies conducted on unemployment in Ethiopia focused on challenges of unemployment and further limiting to the youth, Thus, this study differs by investigating the trend of unemployment rate of the country in relation to economic growth (GDP) in general and regional levels in particular from 2009 -2018.

\section{RESEARCH METHODOLOGY}

\subsection{Research Design}

The research design is used for the study is a mixed of explanatory and descriptive research design. Since the purpose of explanatory research design is to explain and interpret the relationships between two or more aspects of a situation or phenomenon, in this research it enables researchers to explain and interpret the relationship between real GDP and unemployment based on analyzing the trends of growth rate ,

\subsection{Method Data Collection}

The study employs secondary data sources. The secondary data was collected from published NBE annual report 2016-2018 , World bank ,"world development indicators", CSA - UEUS annual reports from 2009 -2018 and CSA-labour force survey report 2013 , and different electronic search engine such as the internet, and other published materials about the research topic.

\subsection{Data Analysis and Presentation}

Quantitative data analysis was done by the use of Statistical Package for Social Scientists (SPSS) software IBM version 21. Growth rate and graphical time series trend analysis were also used to examine the relation between variables . 


\subsection{Model Specification}

In this research, the relation between unemployment rate and the explanatory variable time was used simple time series regression model. Before employing this technique, the researcher had checked the relation between dependent and independent variables were graphically linear.

\section{RESULTS AND DISCUSSION}

\subsection{Trends of real GDP and unemployment growth rate}

Unemployment rate is used to explain the proportion of unemployed population from the total labour force. The rate indicates the number of persons who are ready to participate in the production of goods and services. Unemployment rate is computed as percentage of the unemployed population over the total number of economically active population. Summary of Table .1 presents the trend of unemployment rate and real Gdp from 2009-2018. According to World Bank (2018) "World development indicators" forecasted result reveals that the rate of unemployment at national level is decreased by $23.8 \%$ from $2008 / 2009-2017 / 2018$. While looking the growth trends of unemployment with the subsequent years indicated an amazingly increase of unemployment annual growth rate by the years (2008-2009) and (2016-2017), 7.8\% and 74\% respectively. The result revealed that the majority of economic active labour forces in the indicated years are not participated in the production of goods and services. Likewise, by the years 2015/2016 and 2016/2017 the annual growth rate of unemployment was decreased by $6.7 \%$ and $48.3 \%$ respectively. The result indicated that the economic participation of labour forces in production of goods and services were remarkably positioned higher as compared other years.

Similarly, Real GDP is one of the most important topics in macroeconomics. Its role is to measure the average level of national income adjusted for inflation According to the result of NBE annual report (2018-2019), the rate of real GDP at national level is decreased by 18 . \% from2008/2009-2017/2018 indicated that the country's production of goods and services are fell by $18 \%$. This may be attributed by various reasons like shifts in demand curve, increasing interest rates, government spending reductions and other factors. A reduction of government spending has an impact on unemployment as the government stop of undertaking public projects will result in decreasing unemployment. On the other hand increasing the cost of borrowing or an increasing interest rate will not motivate investors to borrow and invest on various projects, this on the other hand affects the economic participation of labour forces of the country. However, all the aforementioned reasons will require in-depth analysis for future study.

Whereas, looking the growth trends of real GDP in the time serious of data indicated remarkably a negative in real GDP annual growth rate by the years 2010/2011, /2014/2015 and2017 /2018, 23.7\%, 23.1\%and 29.4\% respectively. The result revealed that the $t$ majority of labor forces in the indicated years are not participated in the production of goods and services. Likewise, by the years 2011/2012, 2015/2016 and 2017/2018 the annual growth rate of real GDP were positioned $13.8 \%, 36.3 \%$ and $16.9 \%$ higher as compared to other years. The result indicated that relatively substantial goods and services were produced in the country.

From summery table 1 of time series data one can perceive that the maximum real GDP annual growth rate was $39.3 \%$ in 2016 and likewise, the minimum result of unemployment annual growth rate was (48.3) in 2016. The empirical result illustrated the inverse relation between real GDP and unemployment. Likewise, in 2012 annual rate of GDP increased by $13.8 \%$ while unemployment decreased by (3.9), practically indicated that real GDP has a significant influence on reducing unemployment rate in the indicated year

Table 1.Annual Growth rate of real GDP and unemployment from 2009-2018

\begin{tabular}{|l|l|l|l|l|}
\hline year & Real GDP & $\begin{array}{l}\text { Annual Growth } \\
\text { rate of GDP (\%) }\end{array}$ & $\begin{array}{l}\text { Unemployment rate } \\
(\%)\end{array}$ & $\begin{array}{l}\text { Annual unemployment } \\
\text { growth rate (\%) }\end{array}$ \\
\hline 2009 & 10.6 & 6.1 & 2.35 & 7.8 \\
\hline 2010 & 11.4 & 7.5 & 2.39 & 1.7 \\
\hline 2011 & 8.7 & -23.7 & 2.29 & -4.2 \\
\hline 2012 & 9.9 & 13.8 & 2.2 & -3.9 \\
\hline 2013 & 10.3 & 4.1 & 2.25 & 2.3 \\
\hline 2014 & 10.4 & 1.0 & 2.1 & -6.7 \\
\hline 2015 & 8.0 & -23.1 & 2.01 & -4.3 \\
\hline 2016 & 10.9 & 36.3 & 1.04 & -48.3 \\
\hline 2017 & 7.7 & -29.4 & 1.81 & 74.0 \\
\hline 2018 & 9.0 & 16.9 & 1.81 & 0 \\
\hline
\end{tabular}

Source: NBE annual report (2018-2019), world bank (20!8) :development indicators

As shown from trends in figure. 1 below, Real GDP and unemployment had shown an inverse relation in every two years time, i.e. in the year 2010, 2012, 2014 and 2016. That is to say, an increasing of GDP had a decreasing effect on unemployment rate. Similarly, the year 2009, 2011. 2015 and 2017 results were also revealed that a decreasing of GDP contributing to the decreasing of unemployment. In general, graphical trend analysis 
confirm the low of Okun is holding true Fig 1 Trend comparison of annual real GDP and annual unemployment growth rate .

Figure 1 Trends of Unemployment Rate and real GDP in of the country (2009-2018)

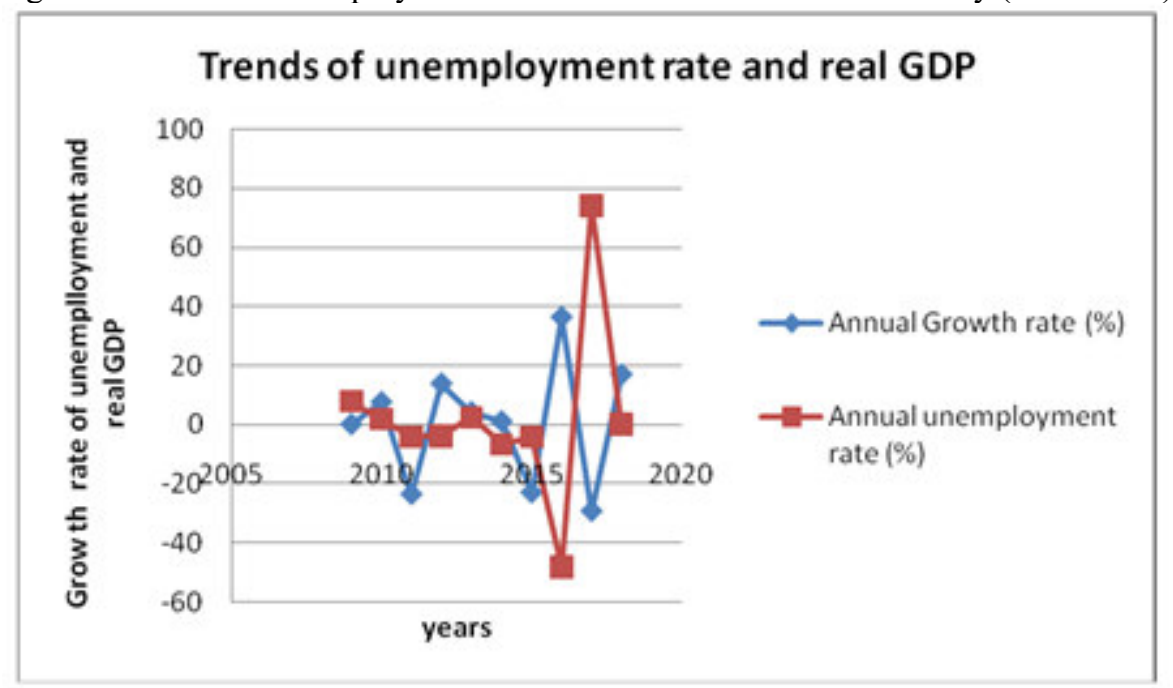

Unemployment Rate at National Urban level

Unemployment rate is the most commonly used indicator of the labour market, is defined as the proportion resulting from dividing the total number of unemployed persons by the corresponding labour force, which itself is the sum of the total persons employed and unemployed. As per the national urban employment- unemployment survey (2009- 2018 ),result unemployment rate in urban areas of the country is summarized in table 2 .The June 2018 survey result of unemployment rate of the national urban level of the country was 19.1 percent. This means that about 19 persons are unemployed out of 100 economically active persons. As shown below in the table. The total unemployment rate depicts a declining trend from 20.4 percent in 2009 to 17.5 percent in 2012 and thereafter increases from 16.9 percent in 2016 to 19.1 percent in 2018.

Table 2 .Summery of unemployment rate urban national level by regions

\begin{tabular}{|l|l|l|l|l|l|l|l|l|l|l|l|l|}
\hline \multirow{2}{*}{ year } & \multicolumn{10}{|c|}{ Regions } \\
\cline { 2 - 14 } & CT & TR & AF & AM & OR & SOM & BEN & SNN & GAM & HAR & AA & DD \\
\hline 2009 & 20.4 & 21.1 & 14.6 & 15.5 & 19.2 & 20.2 & 13.6 & 15.5 & 17.3 & 14.4 & 27.9 & 28.8 \\
\hline 2010 & 18.9 & 18.2 & 13.4 & 15.7 & 16.0 & 13.5 & 10.1 & 14.2 & 12.7 & 15.3 & 26.9 & 30.2 \\
\hline 2011 & 18.0 & 18.0 & 17.4 & 19.3 & 14.1 & 17.2 & 9.3 & 11.8 & 7.7 & 13.6 & 25.1 & 22.9 \\
\hline 2012 & 17.5 & 19.4 & 11.3 & 6.5 & 16.7 & 14.5 & 7.1 & 12.4 & 7.8 & 12.2 & 23.0 & 22.7 \\
\hline 2013 & 16.5 & 12.4 & 12.8 & 13.9 & 13.6 & 18.1 & 9.8 & 14.6 & 6.1 & 12.0 & 24.2 & 22.5 \\
\hline 2014 & 17.4 & 18.4 & 12.3 & 17.6 & 16.1 & 14.0 & 6.3 & 12.6 & 8.0 & 12.2 & 23.5 & 22.8 \\
\hline 2015 & 16.8 & 18.6 & 13.2 & 19.0 & 15.5 & 14.9 & 8.3 & 11.5 & 7.6 & 12.2 & 21.2 & 18.1 \\
\hline 2016 & 16.9 & 20.6 & 19.0 & 17.9 & 15.2 & 18.2 & 11.1 & 11.5 & 8.2 & 10.4 & 21.0 & 24.6 \\
\hline 2017 & 18.0 & 24.5 & 17 & 18.8 & 16.6 & 18.6 & 9.15 & 15.1 & 9.5 & 10.2 & 20.1 & 24.6 \\
\hline 2018 & 19.1 & 21.5 & 15.0 & 19.7 & 18.0 & 18.9 & 7.2 & 18.6 & 10.7 & 10.7 & 20.2 & 25.3 \\
\hline
\end{tabular}

Source: urban employment -unemployment survey(2009-2018)

As shown below in figure 2 and figure 3 Trends of Unemployment rate in urban of the country (20092018),depicted that Addis Ababa and Dire Dawa were playing a significant role in increasing an unemployment rate in urban national levels of the country. The trend of unemployment rate of the country total fails below the trends of the aforementioned two urban areas of the country. The result implied that unemployment was a serious problem in the two towns since 2009. Likewise, Oromiya, SNNP and Benishangul-Gumuz had been contributing a significant role in decreasing unemployment rate of urban country total since 2009. As compared to the trends of Addis Ababa and Dire Dawa, the trends of the abovementioned regions fails entirely below the trends of the country total. On the contrary, Tigray ,Afar ,Somali ,Amahara ,Gambella And Harari regions had been contributing a remarkable role in both increasing and . decreasing of unemployment rate for urban country total since 2009. 
Figure 2 Trends of Unemployment Rate of Country total, Addis Ababa and Dire Dawa (2009-2018)

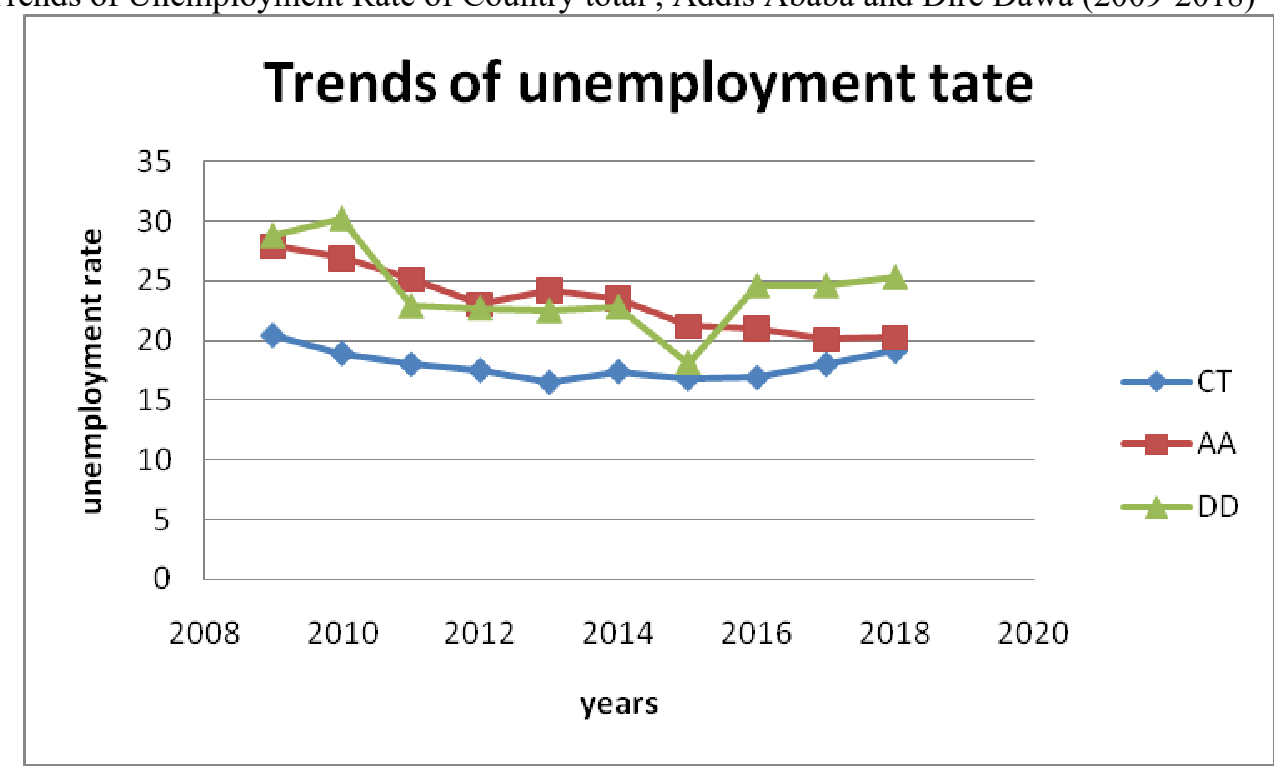

Figure 3 Trends of Unemployment Rate of CT ,Oromiya ,SNNP and BEN (2009-2018)

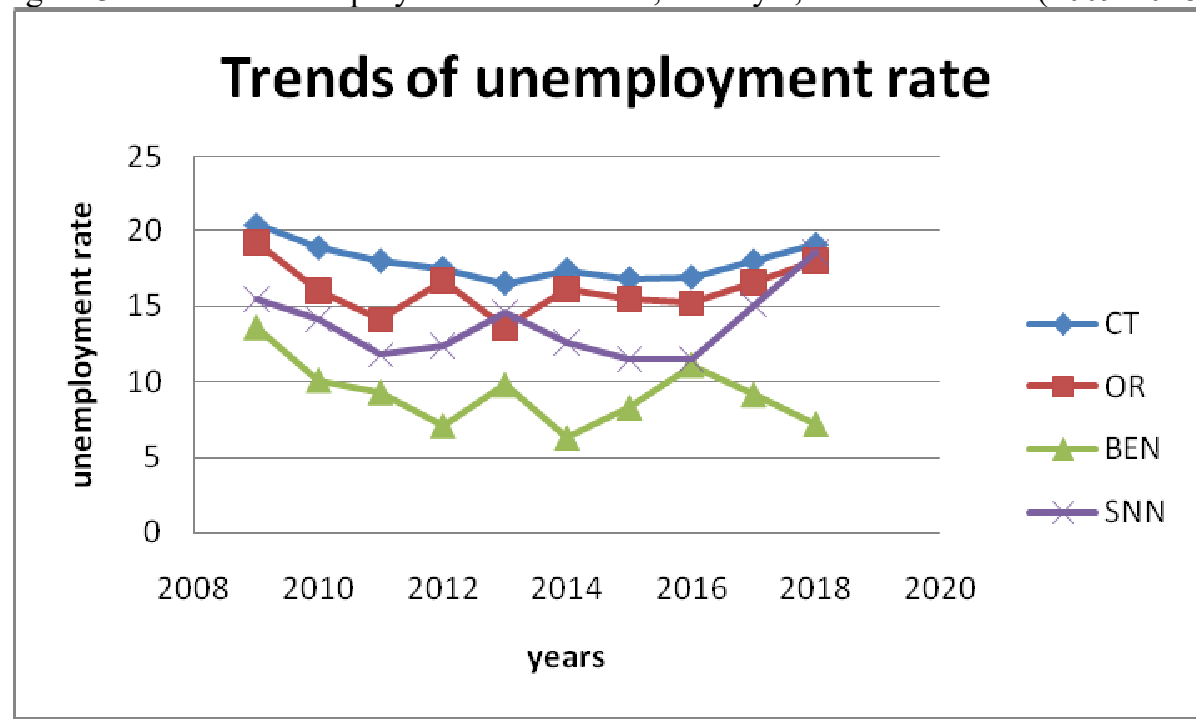

\subsection{Time serious regression and forecasting}

An attempt was made to depict trends of unemployment rate of all the eleven urban regional states against a series of years. However, only time series observations of Addis Ababa and Harari regions were found to have a linear relationship against time.

In figure 4 and 5 it was depicted trends of urban Adiss Ababa and Hrari regions from (2009.-2018). The trends revealed that an approximate linear best fit for the given set of unemployed observations. Subsequently, it was identified a List square method for best estimating coefficients and future unemployment rate of urban Addis Ababa and Hrari (2009-2018). From data of summery table 2 , assuming $2009=1,2010=2$---and $2018=10$ and capturing thecorresponding unemployment rate of the aforementioned regions, 
Figure 4 Trends of Unemployment Rate in urban Addis Ababa (2009-2018)

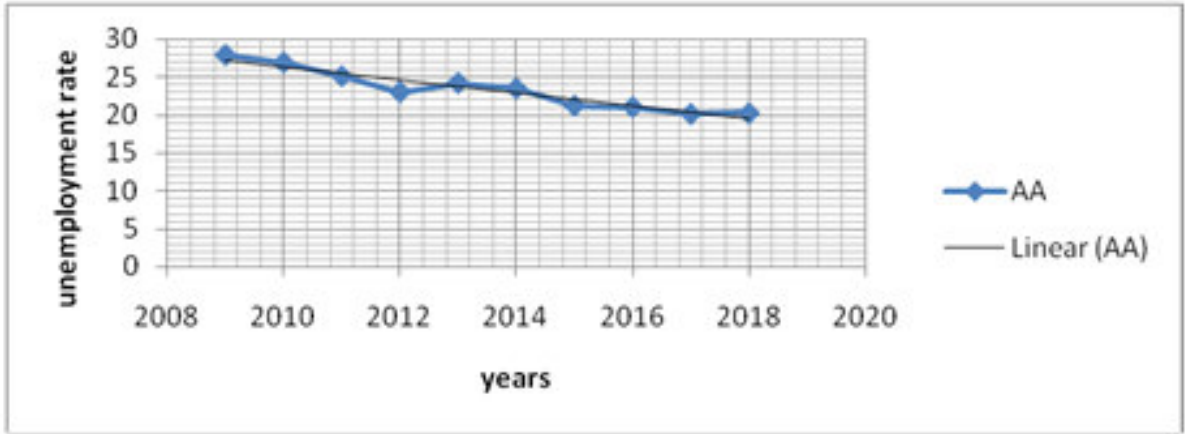

Figure 5 Trends of Unemployment Rat in urban Hrari (2009-2018)

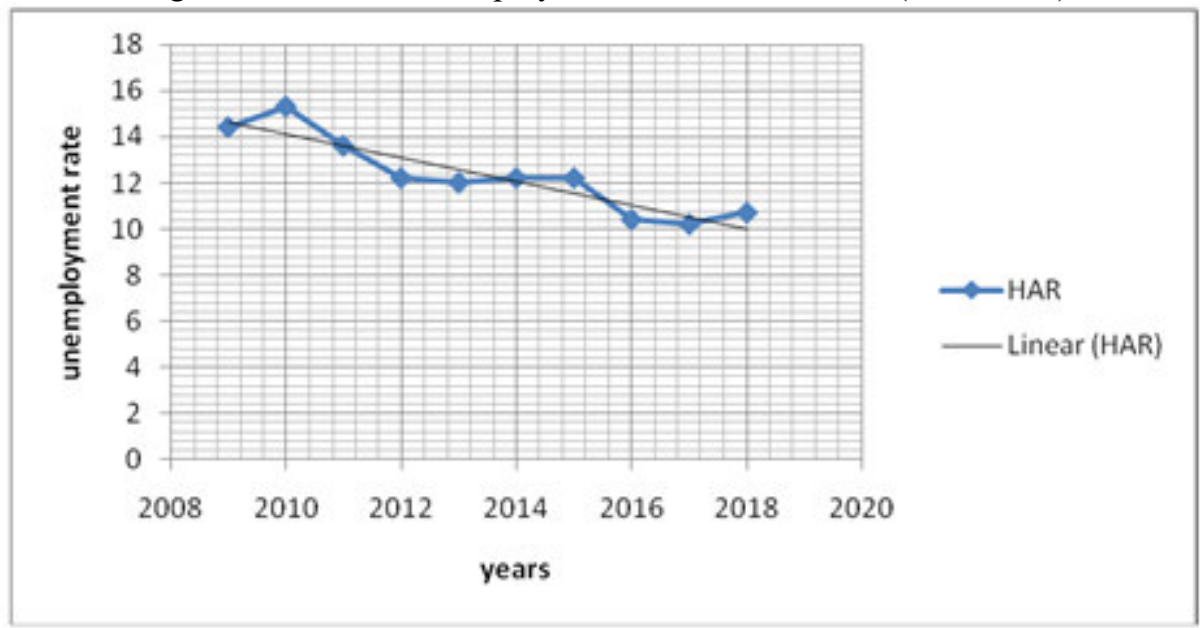

Time sires regression analysis of unemployment rate of Addis Ababa was made using SPSS (version of 20). As a result of which the following simple regression equation was established. As indicated in Table 3 and 4, the model and the coefficient (time) are significant ( $p$ value $=0$ ). Subsequently, $91 \%$ of the variation in the dependent variable (unemployment rate) is explained by the variation of time (years). The estimated time series regression equation for Addis Ababa unemployment rate is $\mathrm{Y}=28.1-.87 \mathrm{t}$. It implies that a one year increase in the independent variable is resulting in a .87 decrease in unemployment. Rate

Based on the estimated equation, unemployment rate of Addis Ababa for example in the year 2020 will be forecasted $17.66 \%$

Table 3 Model Summary unemployment rate of Addis Ababa

\begin{tabular}{|l|l|l|l|l|}
\hline Model & R & R Square & Adjusted R Square & Std. Error of the Estimate \\
\hline 1 & $.959^{\mathrm{a}}$ & .920 & .910 & .82525 \\
\hline
\end{tabular}

Table 4 Coefficients of the model

\begin{tabular}{|c|c|c|c|c|c|}
\hline \multirow[t]{2}{*}{ Model } & \multicolumn{2}{|c|}{ Unstandardized Coefficients } & Standardized Coefficients & \multirow[t]{2}{*}{$\mathrm{T}$} & \multirow[t]{2}{*}{ Sig. } \\
\hline & B & Std. Error & Beta & & \\
\hline $\begin{array}{ll} & \begin{array}{l}\text { (Constant) } \\
\mathrm{T}\end{array}\end{array}$ & $\begin{array}{l}28.093 \\
-.870\end{array}$ & $\begin{array}{l}.564 \\
.091\end{array}$ & -.959 & $\begin{array}{l}49.833 \\
-9.572\end{array}$ & $\begin{array}{l}.000 \\
.000\end{array}$ \\
\hline
\end{tabular}

Likewise, Time sires regression analysis summery of unemployment rate of Harari indicated in Table 5 and 6 , the model and the coefficient (time) are significant ( $\mathrm{p}$ value $=0$ ). Subsequently, $82.5 \%$ of the variation in the dependent variable (unemployment rate) is explained by the variation of time (years). The estimated time series regression equation for is $\mathrm{Y}=15.15-.514 \mathrm{t}$. It implies that a one year increase in the independent variable is resulting in a .514 decrease in unemployment Rate

Based on the estimated equation, unemployment rate of Harari for example in the year 2020 will be forecasted $9 \%$

Table 5 Model Summary of unemployment rate for Harari

\begin{tabular}{|l|r|r|r|r|}
\hline Model & R & R Square & Adjusted R Square & Std. Error of the Estimate \\
\hline 1 & $.919^{\mathrm{a}}$ & .845 & .825 & .70755 \\
\hline
\end{tabular}


Table 6Coefficientsof the model

\begin{tabular}{|l|r|r|r|r|r|}
\hline \multirow{2}{*}{ Model } & \multicolumn{2}{|c|}{ Unstandardized Coefficients } & Standardized Coefficients & \multirow{2}{*}{ S } & \multirow{2}{*}{ Sig. } \\
\cline { 2 - 5 } & \multicolumn{1}{|c|}{ B } & Std. Error & Beta & & \\
\hline \multirow{2}{*}{$\begin{array}{l}\text { (Constant) } \\
\mathrm{T}\end{array}$} & 28.093 & .564 & & 49.833 & .000 \\
$\mathrm{~T}$ & -.870 & .091 & -.959 & -9.572 & .000 \\
\hline
\end{tabular}

\section{SUMMARY, CONCLUSIONS AND RECOMMENDATIONS}

\subsection{Summary of Findings}

This section presents summary of findings based on the results of data analysis in line with specific objectives of the study. The first objective of the study was To analysis descriptively the growth trend relationship between Real GDP and unemployment. Graphical trend analysis of study showed that real GDP and unemployment Growth rate are inversely related all the times during each annual time series data (2009-2018). In general terms, by 2018 , 2016, 2014, 2012 and 2011 real GDP growth rate amazingly rise while the corresponding unemployment growth rate was oppositely failed. Dissimilarly, by 2017, 2015, 2013 and 2010 unemployment growth rates were mounting far than the corresponding real Growth rates of real GDP

The second research objective was to examine the nature of regional urban unemployment growth rate and their contribution to the country total. As the result of which, Addis Ababa and Dire Dawa urban areas had been contributing significantly for the rise of unemployment rate for country urban level. From 2009-2018. As of this time series data, unemployment growth trends of the aforementioned regions had been positioned above the trend of urban country total since 2009. Contrarily, Oromiya, SNNP and Benishangul-Gumuz had been contributing a significant role in decreasing unemployment rate of urban country total since 2009. Because, the trends of unemployment growth rate had been failed below the country aggregate level all the times from 2009-2018.Other regions like Amahara, Afar, Harari, Gamela ,oromiya and TIgray regions were contributing both the rise and decline of unemployment to the country total. Based on graphical trend analysis, unemployment growth trends of Addis Ababa and Harari were found to be liner with time. Subsequently, It was enabled to forecast future unemployment growth rate of the particular regions.

\subsection{Conclusions and Recommendations}

Even if urban Addis Ababa contributed an extraordinary unemployment growth rate for the country total, the inferential statistics time series regression result indicated that Addis Ababa and Hrari urban unemployment growth rate exhibited a significant declining trend since 2009 to 2018.

The study concluded that unemployment and real GDP had an inverse relationship in conformation with Okun's Law and other empirical literature mentioned earlier. Results also depicted that urban unemployment was a major challenge in Addis Ababa and Dire dawa, and in the mean time they had sharing a significant unemployment rate ofor the country total. Since 2009

Based on the summary of findings and conclusions, the following recommendations were worth drawn:

* Since Dire dawa and Addis Ababa are still plying a significant role for an increasing of unemployment rate for the country total or contributing a key role for the declining of real GDP of the country .There for ,the federal and regional government may provide due attention by studding root causes of the problem by devising an appropriate strategy to solve the problems .For example, high rate of migration to urban(urban to urban ,rural to urban ) the prevalence of high landless youth in rural area ,failure to aligned the youth unemployed with the market demand, poor labour market conditions, failure to stimulate investment and lack of accessing startup capital were coined as a major pushing factors to urban unemployment (Abdulkadir H. A ,2014)

* Since the contribution of urban unemployment of Oromiya, SNNP and Benishangul-Gumuz are relatively less to the country total, the government may strengthen the prevailing unemployment decreasing strategy with commitment.

* To sum up, the study recommends that reducing unemployment has a significant role in the growth of GDP. The government may device an appropriate policy how to address the labor market's failure \& improving the labor force productivity through increased level of education \& training, skills for illiterate unemployed \& access to capital \& productive assets that will enable the poor take advantage of the employment generating opportunities. \& other policies that will create conducive condition for increasing investment. More employment generation mechanisms have to be adopted because, how far economic growth reduces poverty depends on how much the growth increases opportunities for employment and on the extent to which the poor can join economic process and take advantage of the improved employment potential. ( Abdulkadir H. A ,2014) 


\section{Reference}

Abdulkadir H. A (2014).Unemployment and Economic Growth: An Empirical Analysis for Ethiopia (1974/75 2013/14).Jimma University

Aminu, Umaru., Manu, Donga., and Salihu, Musa. (2013). An Empirical Investigation in to the Effects of Unemployment and Inflation on Economic growth in Nigeria.Interdisciplinary Journal of Research in Business,Vol. 2. Issue No.12 (pp. 01 -14)/2013. ISSN: 2046 -7141.

Christopoulos,D.,2004.Therelationship between output and unemployment:Evidence from GreekRegions. Stud. Regional Sci., 83: 611-620. DOI: 10.1007/s10110-004-0198-y

CSA (1999, 2005). National Labour Force Survey. A.A., Ethiopia.

CSA (2011-2018) .Urban Employment Unemployment Survey. A.A. Ethiopia

Daniels, K. and D.D.Ejara, 2009.Impact of information asymmetry on municipal bond yields: An empirical analysis. Am. J. Econ. Bus. Admin., 1: 11-20. DOI: 10.3844/ajebasp.2009.11.20

El -Agrody, N. M., Othman, A. Z., \& Hassan, M. B.-D.(2010).Economic Study of Unemployment in Egypt and Impacts on GDP. Nature and Science, 8 (10), 102-111.

Farsio,F.and S. Quade, 2003.An empirical analysis of the relationship between GDP and unemployment. Humanomics,

Fuad M, K., 2010.Economic Growth and Unemployment: An Empirical Analysis,Journal of Social Sciences 7 (2): 228-231, 2011 ISSN 1549-3652

Hussain, T., Siddiqi, M. W., \& Iqbal, A. (2010).A Coherent Relationship between Economic Growth and Unemployment: Empirical Evidence from Pakistan.International Journal of Human and Social Sciences, 1-8.

ILO.(1982).Resolutions Concerning Economically Active Population, Employment, Unemployment and Underemployment Adopted by the 13th International Conference of Labour Statisticians. Retrieved from http://www.ilo.org/wcmsp5/groups/public/dgreports/stat/documents/normativeinstrument/wcms_087481.pdf

ILO.2011.KeyIndicatorsofLabor Market, 7th Edition. Technical report International Labor Organization

Lee, J., 2000. The Robustness of Okun's law: Evidence from OECD countries. J. Macroecon., 22: 331-356. DOI: 10.1016

Maria, Jesus., and Osorio, Amezaga. (2012). Unemployment and Economic Growth in Peru (2001-2012). Colombia University.

Okun, A. M. (1962). Potential GNP: Its Measurement and Significance, American Statistical Association, Proceedings of the Business and Economics Statistics Section, 98-104

Osinubi, T. S. (2005). Macro econometric Analysis Of Growth, Unemployment And Poverty In Nigeria. Pakistan Economic and Social Review, XLOkun, Arthur M. (1962). Potential GNP: Its Measurement and Significance. Cowles Foundation. New Haven: CT: Yale University. Paper 190. III (2), 249 -269.

Osinubi, T. S. (2005). Macro econometric Analysis Of Growth, Unemployment And Poverty In Nigeria.Pakistan Economic and Social Review, XLIII (2), 249 -269.

Seyfried,W. (2004). Examining the relationship between employment and economic growth in ten largest states. Southwestern Economic Review, 1 -12

World Bank (2018). "World Development Indicators.

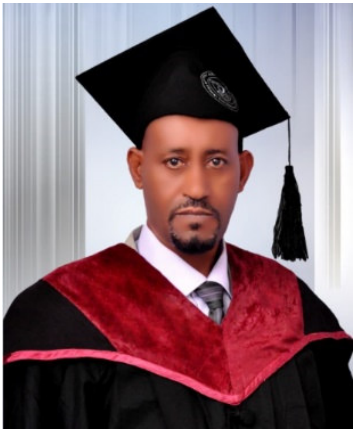

Abiy Serawitu Kassaye

Senior consultant at Dire Dawa

Management and Kaizen Instit

(PhD Candidate) 